\title{
THE POLYCYSTIC OVARIAN SYNDROME AND INFERTILITY: A METABOLIC DISORDER THAT NEEDS EARLY DIAGNOSIS AND TREATMENT
}

\section{Arumugam $\mathrm{K}^{1}$, Majeed NA ${ }^{2}$}

1 Department of Obstetrics and Gynaecology, University of Malaya, Kuala Lumpur, Malaysia

2 Department of Obstetrics and Gynaecology MBBS, Hospital Tengku Ampuan Rahimah, Klang, Selangor, Malaysia

\begin{abstract}
We investigated the association between polycystic ovarian syndrome, dyslipidemia and glucose intolerance in a cross sectional analysis comparing 50 patients with polycystic ovary syndrome and 50 patients without the disease (control group) who were attending the Infertility clinic. Variables of interest were their body-mass index $\left(\mathrm{Kg} / \mathrm{m}^{2}\right)$, fasting and blood glucose levels after a 75 gram oral glucose tolerance test and their total cholesterol $(\mathrm{mmol} / \mathrm{L})$, total triglycerides $(\mathrm{mmol} / \mathrm{L})$, high density cholesterol lipoprotein $(\mathrm{HDL})$ cholesterol $(\mathrm{mmol} / \mathrm{L})$ and, low density lipoprotein cholesterol ( $\mathrm{mmol} / \mathrm{L}$ ) levels. Except for HDL where significantly lower values were observed, significantly higher levels were detected in patients with PCOS than that of the control group. The difference persisted even when the obesity index were adjusted and matched. We conclude that both glucose intolerance and dyslipidemia were significantly associated with PCOS irrespective of the obesity index.
\end{abstract}

KEYWORDS: PCOS, dyslipidemia, glucose intolerance

\section{Correspondence:}

Kulenthran Arumugam, FRCOG

Medical Education and Research Development Unit

University of Malaya

50603 Kuala Lumpur, Malaysia

Email: akulenthran@gmail.com

Tel: 60379673791

\section{Introduction}

The polycystic ovary syndrome (PCOS) affects up to $10 \%$ of women during the childbearing years [1]. It is commonly seen in infertile patients. The disease is characterized by insulin resistance and hyperandrogenism [2]. While insulin resistance may result in glucose intolerance, it takes both insulin resistance and the hyperandrogenic state to cause the dyslipidemia seen in these patients [3-6]. The long term complications of these abnormalities are an increased risk to cardiovascular events and thus cardiovascular morbidity, especially in women with excessive body weight [7].

Interestingly, these metabolic aberrations in glucose intolerance and dyslipdemia have been reported to vary with race and ethnicity $[8,9]$. Most of the studies however appear to be confined to Western or Hispanic populations; as recent reports in Asian populations are not common.

Obesity is a common feature of the disease but based on the accepted definition for PCOS \{10], it is not one of the criteria for a diagnosis. Although several reports on the association between glucose intolerance and/or dyslipidemia with obesity have been demonstrated $[7,11]$, others have reported otherwise $[12,13]$.

The purpose of the study therefore was to investigate if glucose intolerance and dyslipidemia were present in our multi-ethnic population suffering from PCOS regardless, of their obesity index.

\section{Patients and methods}

A cross sectional analysis of 50 patients with PCOS was conducted against 50 patients without PCOS. Both cohorts were recruited whilst they were attending the 
Infertility clinic at the Tengku Ampuan Rahimah Hospital Klang, Malaysia from June 2008 to July 2009. Serial selection of subjects made during the recruitment period was performed without exclusion.

PCOS was defined [10] as a patient having any two of the following three criteria: (1) oligo or anovulation as evidenced by luteal phase progesterone; (2) clinical and/or biochemical signs of hyperandrogenism as evidenced by a modified Ferriman and Gallwey hirsutism score of six or more and persistence of acne during the third decade of life and (3) polycystic ovaries as defined by ultrasonography i.e. 12 or more peripheral follicles or increased ovarian volume of $>10 \mathrm{~cm}^{3}$. Controls consisted of patients who did not meet the above criteria nor were diagnosed with any other known medical condition.

Patients had their body-mass index measured $\left(\mathrm{Kg} / \mathrm{m}^{2}\right)$ and, underwent an oral glucose tolerance test using 75 gram oral glucose solution. To assess dyslipidemia, fasting blood levels of total cholesterol $(\mathrm{mmol} / \mathrm{L})$, total triglycerides $(\mathrm{mmol} / \mathrm{L})$, high density cholesterol lipoprotein cholesterol ( $\mathrm{mmol} / \mathrm{L})$, low density lipoprotein cholesterol ( $\mathrm{mmol} / \mathrm{L}$ ) was also performed.

Patients who were specifically excluded were those who were diagnosed to be glucose intolerance or diabetes, those who were current or immediate past users (within 3 months) of hormones that could interfere with their ovarian functions e.g. clomiphine citrate and those who were on insulin- sensitizing agents (e.g. metformin) or any form of corticosteroids. Also excluded were patients with other causes for hyperandrogenism e.g. congenital adrenal hyperplasia, Cushing's syndrome or androgen-secreting tumours. The diagnosis for these conditions may be based on either ultrasound, radiological and hormonal assay criteria.

Statistical analysis. Continuous data were compared using the two sample Students $t$-test after satisfying the Shapiro-Wilks test for normality. To adjust for obesity as a confounder, multiple regression analysis was done with the covariate obesity coded as a dichotomous variable $\left(=<25\right.$ and $>25 \quad \mathrm{Kg} / \mathrm{m}^{2}$ respectively). Stata (Ver.10:Timberlake, USA) Statistical Software was used for analysis. Significance is set with a $p$ value of $<0.01$.

\section{Results}

Patients consisted of 50 Malays (22 in the PCO group), 7 Chinese (2 in the PCPO group) and 43 Indians (26 in the PCO group). The findings of interest are summarized in the Table. There was no difference in the age in the PCOS and control groups. Glucose intolerance was significantly greater in the PCOS group. All parameters of dyslipidemia were also found to be significantly greater in the PCOS group. Obesity had a minimal impact on the results.

Table: Features of glucose intolerance and dyslipidemia in patients with polycystic ovarian syndrome and in controls

\begin{tabular}{lcccc}
\hline & $\begin{array}{c}\text { PCOS }(\mathrm{n}=50) \\
\text { Mean } \pm \mathrm{SD}\end{array}$ & $\begin{array}{c}\text { Controls }(\mathrm{n}=50) \\
\text { Mean } \pm \mathrm{SD}\end{array}$ & P value & $\begin{array}{c}{ }^{*} \text { Adjusted } \\
\text { P value }\end{array}$ \\
\hline Age in years & $27.8 \pm 3.6$ & $28.0 \pm 3.4$ & 0.71 & \\
Obesity index & $31.9 \pm 3.7 \mathrm{~kg} / \mathrm{m}^{2}$ & $23.1 \pm 1.8 \mathrm{~kg} / \mathrm{m}^{2}$ & $<0.001$ & 0.006 \\
Fasting blood glucose & $5.7 \pm 1.6 \mathrm{mmol} / \mathrm{l}$ & $4.7 \pm 0.58 \mathrm{mmol} / \mathrm{l}$ & $<0.001$ & $<0.001$ \\
Two hour blood glucose & $7.5 \pm 1.5 \mathrm{mmol} / \mathrm{l}$ & $5.4 \pm 1.2 \mathrm{mmol} / \mathrm{l}$ & $<0.001$ & 0.001 \\
Total cholesterol & $5.7 \pm 0.78 \mathrm{mmol} / \mathrm{l}$ & $4.9 \pm 0.8 \mathrm{mmol} / \mathrm{l}$ & $<0.001$ & 0.001 \\
Total triglyceride & $1.5 \pm 0.59 \mathrm{mmol} / \mathrm{l}$ & $1.02 \pm 0.42 \mathrm{mmol} / \mathrm{l}$ & $<0.001$ & 0.003 \\
Low density lipoprotein & $3.8 \pm 0.71 \mathrm{mmol} / \mathrm{l}$ & $3.04 \pm 0.68 \mathrm{mmol} / \mathrm{l}$ & $<0.001$ & 0.008 \\
High density lipoprotein & $1.2 \pm 0.25 \mathrm{mmol} / \mathrm{l}$ & $1.47 \pm 0.32 \mathrm{mmol} / \mathrm{l}$ & $<0.001$ & \\
\hline
\end{tabular}

${ }^{*}$ Adjusted for obesity 


\section{Discussion}

The results of the present study indicate that glucose intolerance and dyslipidemia are significantly associated with PCOS. Obesity had only a marginal impact on the results. These results were comparable to that previously reported [3].

Although we showed that obesity had only a marginal impact, others have shown that the effect of PCOS on plasma lipids was amplified due to higher BMI [11]. In a review of studies comparing overweight obese PCOS with matched controls, a less favourable lipid profile was observed in the obese group in two thirds of studies. Lowered HDL-cholesterol was the most prominent difference seen followed by higher triglycerides and finally higher LDL-cholesterol [11].

Although the pathogenesis of PCOS is still elusive, the endocrinology abnormality may have been attributed to an increase in luteinising hormone release which results in the increase in ovarian androgen production, a process that can be aggravated by insulin resistance [11]. The association between insulin resistance and PCOS is well-established, affecting about $50 \%$ to $70 \%$ of PCOS women [14]. In a review, between $33 \%$ and $47 \%$ of these women have associated metabolic syndrome the essential feature being dyslipidemia [15]. The mechanism by which dyslipidemia occurs has been postulated as a multistep process involving hyperandrogenism, anovulation and insulin resistance [11].

Others also report that glucose intolerance is significantly increased in patients with PCOS, ranging from $18 \%$ to $40 \%$ of patients. There is also an increased prevalence of Type 2 diabetes; $15 \%$ when compared to the general population of $2.3 \%$ [16]. The underlying cause for the glucose intolerance is most probably due to insulin resistance. Because of insulin resistance plays a central role in the pathogenesis of glucose intolerance, the use of metformin has become the drug choice for treating this condition [11].
Notwithstanding the robust finding of the results this study, several limitations were identified. The control group limited to women seeking infertility treatment, which may have been the result of indirect hormonal imbalances. This may have caused biasness in the selection of the represented population. In addition, convenience sampling and not randomized selection was used, which may have further compounded the problem. Although limited to only 50 subjects in each group, the analyses of the data obtained from this study demonstrated, with a high degree of confidence, significant statistical differences between the groups.

Based on the Rotterdam Classification system, neither abdominal obesity, insulin resistance nor dyslipidemias are included as a criteria for a diagnosis of PCOS [10]. However, because of the increasing evidence that these abnormalities are common features of PCOS, comments have been made about the need to broaden the diagnostic criteria by including them [17].

In conclusion, our results demonstrate with a certain degree of limitation that the presence of dyslipidemia and glucose intolerance exists in infertile women with PCOS. It is therefore important that we do not ignore these factors in managing patients with PCOS. Regular review of their metabolic status and advice on preventive measures of the long term complications should therefore be emphasized.

\section{References}

1. Lobo RA, Carmina E. The importance of diagnosing the polycystic ovary syndrome. Ann Int Med 2000; 132:989-93.

2. Dunaif A. Insulin resistance and the polycystic ovarian syndrome: mechanism and implications. Endocr Rev 1997; 18:774-800.

3. Apridonidze T, Essah PA, Inorno MJ, Nestler JE. Prevalence and characteristics of the metabolic syndrome in women with Polycystic Ovarian 
Syndrome. J Clin Endocrinol Metab 2005; 90:192935.

4. Bickerton AS, Clark N, Meeking $D$, et al. Cardiovascular risk in women with polycystic ovarian syndrome(PCOS). J Clin Pathol 2005; 58:151-4.

5. Essah PA, Nestler JE. Metabolic syndrome in women with polycystic ovary syndrome. Fertil Steril 2006; 86(Suppl 1): S18-9.

6. Guzick DS. Cardiovascular risk in PCOS. J Clin Endocrinol Metab 2004; 89:3694-5

7. Rizzo M, Berneis K, Spinas G, Rini GR, Carmina E. Long-term consequences of polycystic ovary syndrome on cardiovascular risk. Fertil Steril 2009; 91:1563-6.

8. Wijeyaratne $\mathrm{CN}$, Balen $\mathrm{JH}$, Barth $\mathrm{JH}$, Belchetz PE. Clinical manifestations and insulin resistance in polycystic ovary syndrome (PCOS) among South Asians and Caucasians: is there a difference? Clin Endocrinol 2002; 57:343-50.

9. Essah PA, Nestler JE, Carmina E. Differences in dyslipidemai between American and Italian women with polycystic ovary syndrome. J Endocrinol Invest 2008; 31:35-41.

10. Rotterdam ESHRE/ASRM-Sponsored PCOS Consensus Workshop Group. Revised 2003 consensus on diganostic criteria and long-term health risks related to polycysystic ovarian syndrome. Human Reprod 2004; 19:41-7.
11. Westerveld HE, Hoogendoorn $M$, de Jong AWF, Goverde AJ, Fauser BCJM, Dallinga-Thie GM. Cardiometabolic abnormalities in the polycystic ovary syndrome: pharmacotherapeutic insights. Pharmacology \& Therapeutics 2008; 119:223-41.

12. Legro R, Allen R, Kunselman MA, Andrea Dunail MD. Prevalence and predictors of dyslipidemia in women with polycystic ovary syndrome. Am J Med 2001; 111:607-13.

13. Graf M, Brown V, Richards $C$, Meissner L, Dunaif $A$. The independent effects of hyperandrogenemia, hyperinsulinemia, and obesity on lipid and lipoprotein profiles in women. Clin Endocrinol 1990; 33:119-31.

14. Legro RS, Castracane VD, Kauffman RP. Detecting insulin resistance in polycytic ovarian syndrome: purposes and pitfalls. Obstet Gynecol Surv 2004; 59:141-54.

15. Essah PA, Wickham EP, JE N. The metabolic syndrome in polycytic ovary syndrome. Clin Obstet Gynecol 2007; 50:205-25.

16. Ehrman DA, Barnes R, Rosenfiled R, Cavaghan M. The prevalence of impaired glucose tolrerance and diabetes in women with polycystic ovarian syndrome. Diabetes Care 1999; 22: 141.

17. Azziz R. Controversy in clinical endocrinology: diagnosis of polycystic ovarian syndrome: the Rotterdam criteria are premature. J Clin Endocrinol Metab 2006; 91:781-5. 